\title{
Do they know that they know? EFL learners' attitude towards concept mapping in listening comprehension
}

Sabbaghan, Soroush $\bowtie$

Science and Research Branch, Islamic Azad University, Tehran, Iran (publications@soroushsabbaghan.com) Ansarian, Fatemeh

Damavand Branch, Islamic Azad University, Tehran, Iran (nahal_ir2001@yahoo.com)

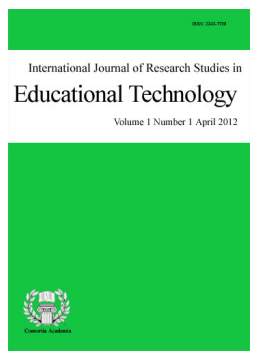

ISSN: 2243-7738 Online ISSN: 2243-7746

OPEN ACCESS

\section{Abstract}

The ability to listen efficiently plays a key role in oral communication for ESL/EFL students. Scholars in the field have suggested many strategies and methods to improve listening comprehension. One of these methods is concept mapping. However, whether the students actually realize that concept mapping may improve their listening comprehension has not been explored. Therefore, the present study was designed to investigate the effect of applying concept mapping techniques on EFL learners' attitudes towards using this technique in listening comprehension. To this end, $146 \mathrm{EFL}$ students at the elementary level of language proficiency were selected, and they were randomly assigned to experimental and control groups. In the course of eight sessions, the experimental group went under an intervention of concept mapping, during which concept maps were introduced, and the listening paper of the KET was used as practice material. Descriptive statistics and a paired sample t-test that was utilized to analyze the data established that the two groups were significantly different in their listening comprehension ability. In order to assess the participants' attitudes, before and after the treatment, the researchers administered a self-assessment questionnaire to the participants in the experimental group. The results indicated that the participants felt that using concept mapping strategies significantly improved their listening comprehension. The fact that the participants made this realization indicates that using concept mapping strategies raised the learners' awareness regarding their listening, and may lead to learner autonomy.

Keywords: concept mapping; learners' attitude; awareness; oral communication; quantitative survey 


\section{Do they know that they know? EFL learners' attitude towards concept mapping in listening comprehension}

\section{Introduction}

In the Iranian EFL educational setting, it is unfortunate that developing listening skills has not received the emphasis that it has deserved. Many Iranian EFL learners believe that paying more attention to their improvement of pronunciation, vocabulary, and grammar is far more important than developing listening comprehension. Ironically, they often say that focusing on these language components helps achieve competence in communication. The importance of developing listening comprehension has been emphasized by an array of scholars (Brown, 2007; Celce-Murcia \& McIntosh, 1991; Nunan, 2002; Rost, 2001). There are now many books and courses presenting different methods that may improve the listening comprehension of learners. For example, Ur (1984) offers more than 30 types of exercises for teaching listening. Similarly, Rost (1991) has proposed more than 25 various activities.

If EFL students do not learn to listen effectively, they will have problems with oral communication. Therefore, in the last two decades, EEL/ESL researchers have been experimenting with methods and techniques encompassing top-down interpretation and bottom-up processing models. According to Goh (2002), some of the more successful techniques resulting in effective listening include: (a) brainstorming, (b) concept mapping, (c) prediction, (d) guided question, and (e) skimming. These techniques are the practical manifestations of the schema theory, whose advocates hypothesize that comprehension relies significantly on the listeners' successful activation of their prior knowledge (schemata).

Concept mapping is a schema building strategy that aids learners organize information through the use of visual aids. A concept map is a diagram that shows the relationship among concepts. While using concept mapping strategies, the learner tries to access their background knowledge by sorting them in classified ordination. This process helps the learner to retrieve memorized knowledge (Beyerbach \& Smith, 1990; Chang, Sung, \& Chen, 2001, 2002; Conradty \& Bogner, 2012; Erdogan, 2009; Igwebuike, 2012; Novak, 1990; Novak, Bob Gowin, \& Johansen, 1983; Tripto, Assaraf, \& Amit, 2013; Tzeng, 2010; Yen, Lee, \& Chen, 2012).

While the learners are developing a concept map during listening, they need to corroborate the concept of the topic. To do so, they must comprehend sentences and paragraphs, which allow them to arrange the concepts around the main concept. In this process, the learners must identify the relationships of some concepts and produce the appropriate links, and finally comprehend the whole passage. This construction process is bottom-up listening comprehension. Moreover, when mapping, learners need to activate their passive, personal, and prior schemata to organize and realize the new message through which they will probably develop new schemata. When mapping is complete, the learners can review the relationships among concepts. In doing so, they are utilizing prior schemata in order to construct meaning, which is in essence top-down processing. In conclusion, developing a concept map integrates both bottom-up and top-down processing models (Kintsch \& Van Dijk, 1978).

The number of studies investigating the effects of concept mapping on listening comprehension is surprisingly limited. In a research by Nunan (1999), the use of concept mapping technique had a positive effect on the listening comprehension of learners. In this study, learners were put into one of three groups, and asked to listen to an interview. The first group was required to listen to the tape and take notes, then answer the comprehension test. The second group was required to listen to the tape and check off the key words and phrases and then complete the comprehension test. Finally, the third group was required to listen to the tape and not only check off the key words but also find the relationship between those words and complete a concept map. The study showed that the additional depth of processing in the third group resulted in superior comprehension. 
Do they know that they know? EFL learners' attitude towards concept mapping in listening comprehension

Similarly, in a study conducted by Fahim and Amjadiparvar (2012), the effects of concept mapping on Iranian EFL learners' listening comprehension at the upper-intermediate level was investigated. The results showed that listening performance can be improved through the utilization of concept mapping strategy.

There have been several studies, however, that evaluated the effectiveness of concept maps as a teaching and learning instrument. In ESL reading, concept mapping was found to be beneficial for learners in the areas of reading comprehension, recalling, and organization (Ruddell \& Boyle, 1989; Scanlon, 1992). The positive effects of concept mapping on ESL/EFL writing have also been documented (Kinchin \& Hay, 2005; Ojima, 2006; Sturm \& Rankin-Erickson, 2002; Talebinezhad \& Negari, 2007). Finally, concept maps have been found to be more effective for knowledge retention (Mayer, 1996; McCagg \& Dansereau, 1991).

There are two approaches to concept mapping in the classroom: learner-constructed concept map and expert-construct concept map (Liu, Chen, \& Chang, 2010). When using learner-constructed concept map strategy, the teacher asks the students to construct a concept map (after it is introduced and demonstrated). This strategy aids the students to recognize relationships, textual structures, and important concepts. (Boyle \& Weishaar, 1997; McCagg \& Dansereau, 1991). The expert-constructed concept map is often used for practice and training in the comprehension of texts or passages. Because expert-constructed maps are developed by the instructor, they have a time-saving advantage over learner-constructed concept maps (Jonassen, Beissner, \& Yacci, 1993). Both these strategies can be useful in the class, and the appropriate alternation of using these two methods may contribute to meaningful learning.

Concept mapping may be conducted individually, or in groups. Individually developed concept maps allow students to discover important concepts and relations on their own time and terms. Therefore, these concept maps may allow the students to organize their own understanding. Studies have indicated that students who use individual mapping perform better on comprehension tests and have lower anxiety then those who do not (Jonassen et al., 1993; Ojima, 2006; Sturm \& Rankin-Erickson, 2002; Talebinezhad \& Negari, 2007). Collaborative mapping involves building or sharing a concept map as a group. During this concept mapping process, students can interact, transfer, and exchange opinions with other members of their group. Some research studies suggested that collaborative mapping can improve social communication skills, and enhance learning motivation. (Guvenc \& Acikgoz, 2007; Hwang, Shi, \& Chu, 2010; Kwon \& Cifuentes, 2009).

A missing component in the studies on the effects of concept mapping on language learning is the investigation of whether the participants actually realize that concept mapping is a useful tool for developing their language skills. In other words, although the studies showed that concept mapping could improve the learners' reading, writing, and listening abilities, the participants of the studies probably remained ignorant of this fact. Investigating the attitudes of learners towards concept mapping is important because the process of mapping is believed to have several beneficial implications (see Horton et al., 2006 for summary). If learners believe that concept maps are just another graphic representation of information, they will most likely avoid using this strategy during their language learning process. In such a case, those learners will deprive themselves from using a very powerful learning tool. There have been some studies that investigated the attitudes of students towards concept mapping. For example, Okebukola and Jegede (1989) reported that the use of concept mapping reduces anxiety of students who were studying subject matter that they perceive to be difficult. Jegede, Alaiyemola, and Okebukola (1990) also reported similar results, but suggested that the reduction of anxiety towards the subject matter was more prominent in males than in females.

In the EFL/ESL setting, there have been very few studies that investigated students' attitudes towards the use of concept mapping as a strategy to improve language learning skills. For example, Chularut and DeBacker (2004) reported that the use of concept mapping improves students' self-monitoring and self-efficacy, which is an indication of the students' positive attitude towards concept mapping. Moreover, a review of literature revealed that there has not been an investigation involving concept mapping, listening comprehension, and the measurement of the learners' attitudes toward using concept mapping as a tool for developing listening 
Sabbaghan, S. \& Ansarian, F.

comprehension. It is hypothesized that the introduction and practice of concept mapping techniques can be used to raise awareness about the effectiveness of concept mapping strategies. The present study was an investigation of the effect of concept mapping on EFL learners' attitudes towards using this strategy in listening comprehension.

\section{Methodology}

\subsection{Participants}

The participants of this study included 56 male and 90 female EFL learners. The participants were selected based on the scores they received on the Oxford Placement Test (OPT; Allen, 2004). Prior to the study, 157 candidates took the OPT, however, only 146 obtained scores ranging from 105 to 119 , which according to the OPT, designates them as elementary learners. The participants were randomly assigned to experimental and control groups of 73 members each. The participants' age ranged from 15 to 28 years, and all were native speakers of Persian. The study was conducted in two different language institutes. The participants in each institute were randomly assigned to classes of about 16 pupils.

In order to ensure the homogeneity of the experimental and control groups in terms of language proficiency, an independent samples $t$-test was used to compare the means of the OPT scores to determine whether the experimental and control groups come from the same population. The results of the $t$-test showed that there was no significant difference in the language proficiency level of the experimental and control group $\mathrm{t}_{(144)}=-1.84, p$ $=0.77$.

The listening paper of the KET was administered to investigate whether the experimental and control groups had similar abilities in listening comprehension. Both the experimental and control group answered listening comprehension questions without using concept mapping techniques. In order to test the homogeneity of the participants listening ability an independent samples $t$-test was computed. The results showed that there was no significant difference between the scores of the experimental and control groups $\mathrm{t}_{(144)}=-1.44, p=0.153$. Thus, it can be concluded that regarding listening comprehension ability, members of the control and experimental groups did not differ.

\subsection{Instrumentation}

In order to provide data and subsequent analysis, several instruments were used in this study.

\section{Oxford placement test}

The Oxford Placement Test (Allen, 2004) was administered in order to identify the participants' level of language proficiency. The OPT consists of listening and grammar sections.

The listening paper of Key English Test (KET)

The KET is set at Level A2 of the Common European Framework of Reference. Level A2 corresponds with OPT's Elementary level (Allen, 2004). For this reason it was selected as a suitable test to examine the participants' skill level in listening comprehension. The listening paper of different KETs was used as a pretest, a post-test and practice material for when the participants were receiving instructions on how to use concept maps. The pretest and the post-test were parallel tests with the same nature and characteristics.

The listening paper was comprised of five parts. Part 1 consists of five short conversations, however for the purposes of this study only one conversation was used for the pretest and post-test. For the conversations used, there was a question which contained three pictures (marked A, B, and C). The participants had to listen to the conversations and choose the right answer. Part 2 encompassed a longer conversation and two lists of words. The 
Do they know that they know? EFL learners' attitude towards concept mapping in listening comprehension

participants were instructed to listen to the conversation and match two lists of items. In Part 3, the participants were asked to listen to a conversation and answer some multiple choice questions. For Part 4 , the participants were required to listen to a recording and write down the information it presented in a form of a message or notes. The last part of the listening section included a monologue. The participants were asked to listen to a recording and complete a message or notes. The test required about 40 minutes to complete.

\section{Hand out}

After the participants were formally exposed to concept mapping strategy for the first time, the researchers distributed a handout for the participants as supplementary material. The handout consisted of a brief description of concept maps as developed by Novak et al. (1983), and the procedures to follow for constructing effective concept maps. The hand out contained detailed information regarding collaborative and fill-in-the-map techniques, which were specifically selected for the purposes of the current study in view of the fact that they were more manageable taking into account the context of the research. The handout was written in Persian, because an English version would have been too difficult to comprehend for the participants.

\section{Self-assessment questionnaire}

Before the administration of the treatment and also at the end of the treatment, the experimental group's attitude towards concept mapping was evaluated using a self-assessment questionnaire. The purpose of using the questionnaire before the treatment was to observe whether any of the participants has any prior knowledge regarding concept maps. After the treatment, the questionnaire was used to investigate whether the participants realized that using concept mapping influenced their listening comprehension ability. Ten statements adapted from Arnaudin, Mintzes, Dunn, and Shafer (1984) were devised (see Appendix A). The participants were asked to rate each statement about concept mapping on a 5-point Likert scale. The choice strongly disagree was allocated zero points, and four points was considered for strongly agree. The scores for the other three choices were scaled accordingly.

In order to reduce response sets and response bias, the questionnaire included two divergent statements (expressing negative attitude). The first statement was "It is difficult to understand concept mapping" and the fourth statement was written as "I think concept maps are a waste of time." All other statements expressed positive attitude towards concept mapping. These statements were included so that the researchers would be able to calculate the correlation coefficient between the scores for these statements and the total score (not including the scores for these two statements). A negative correlation would indicate that the scoring was most likely not random. Furthermore, for the calculation of the total score, the 5-point Likert scale was reversed for the two divergent statements. In other words, the choice strongly disagree was given four points, and no points were allocated for the choice strongly agree. The researchers intentionally avoided using more than two divergent statements because they hypothesized that as the proficiency level of the participants was elementary, further divergent statements would result in confusion. The participants were also asked to comment further on each statement if necessary. They were also required to provide comments on their overall impression of using concept maps in listening tasks.

\subsection{Data collection procedure}

To accomplish the purpose of the study, the following procedure was carried out. First, the OPT was administered and the participants were selected. In the first session in which the researchers and the participants met, the pretest was administered to both the experimental and control groups. In this phase of the study, both the experimental and control groups answered listening comprehension questions without using concept mapping techniques. Next, data on the participants' familiarity of concept mapping was gathered from the experimental group via the self-assessment questionnaire. The researchers asked that the participants provide honest feedback to assess whether the participants in the experimental group had any prior experience with using concept maps. Once the questionnaire was completed, it was returned to the researchers. No time limited was 
Sabbaghan, S. \& Ansarian, F.

imposed for this section.

After the completion of the questionnaire, the treatment was administered to the experimental group. In Session 1, the researchers, who were in different language institutes, provided a brief introduction to concept maps and explained what was expected of the participants. At the end of the session, the researchers provided the participants with the Handout on concept mapping. Treatments continued for 8 sessions and each lasted for about 60 minutes.

In Session Two, the researchers presented a brief review of the previous session. The researchers reviewed concept maps using the Handout. Subsequently, the researchers introduced fill-in-the-map and collaborative concept mapping techniques. First, they explained the fill-in-the-map technique based on an introduction provided by Schau, Mattern, Weber, Minnick, and Witt (1997). In this approach key words are omitted by the instructor in a skeleton map and the learners are supposed to listen attentively to a passage and jot down the key words in so-called blank spaces. This particular technique was selected because the researchers anticipated that as the participants were still at the early stages of learning, constructing a whole concept map would be very challenging.

Next, the second concept map technique - collaborative concept mapping - was introduced to the participants. In collaborative concept mapping, learners form groups and either try to construct a concept map or share their completed version of a concept map with other members of their group. This techniques was selected because it is suggested that collaborative concept mapping may reduce some of the anxiety of low language proficiency learners (Ruiz-Primo, 2000). It may also encourage students to reflect, transfer, interact, and exchange their opinions. In order to conduct collaborative concept mapping, the participants are asked to form groups of three or four. Group members were asked to work on concept maps as group work.

Session Two continued with practice using recorded dialogues from KET. The participants were given concept maps related to three dialogues. For the first two dialogues, a completed version of a concept map was presented to the participants (see Figure 1 for sample). Next, one more dialogue was played, but for this dialogue, the participants were provided with a partially incomplete concept map, and they had to listen to the conversations and fill in the blank nodes. When the concept map was complete, they conducted group work within the framework of collaborative concept mapping. Finally, a multiple choice question containing three pictures for the third dialogue was administered to the participants and they, individually, continued the exercise by selecting the correct answer. The answer was then checked as a class activity.

Sessions Three through Eight followed a similar procedure. The class began with a review of the preceding sessions. It proceeded with the participants listening to recordings, completing a concept map with blank nodes, conducting collaborative concept mapping, and selecting the correct answers of the KET listening questions. As the sessions progressed more nodes were left black for the student to complete. Eventually by session 8 , almost all the nodes were left blank. In total, nine concept maps were completed as part of the practice phase of the study. The answers to the KET listening questions were provided at the end of every session. In the control group, the same KET listening papers used as practice material for the experimental group was administered to the participants for eight sessions. The participants in this group listened to the recordings twice (so as to have relatively as same amount of exposure to the listening as the experimental group) and answered the related questions. While listening to the recordings, the participants were free to take notes. All the answers where checked as a class activity at the end of every session.

In the last session (Session 9), the researchers began with a brief review of previous sessions. Then, the listening paper of KET was administered as a post-test to the control and to the experimental group. In the experimental group, the participants listened to a recording and completed a skeleton concept map, that of which almost all the nodes were blank. Two minutes was allocated for students to review their concept map. Then, the participants were asked to answer the standard questions of the KET for the recording they had just heard. An appropriate amount of time was allocated for participants to answer the questions, and then the next recording 
Do they know that they know? EFL learners' attitude towards concept mapping in listening comprehension

was played. There were five listening extracts, so the members of the experimental group were given five concept maps to complete. Collaborative concept mapping was not included in this session, because it was not feasible and the learners were familiar with the procedure for fill-in-the-blank mapping, thus they were not expected to be very anxious.

For the post-test in the control group, the participants were asked to listen to the same recordings played for the experimental group and they were encouraged to take notes while listening. After listening to each recording only once, an appropriate amount of time (the same about allocated for the experimental group) was given for the participants to answer the KET questions. After the post-test, the researchers re-administered the self-assessment questionnaire to the experimental group. The researchers asked the participants to provide feedback on whether concept mapping had affected their listening comprehension ability. The questionnaires were returned to the researchers upon completion and no time limit was imposed.

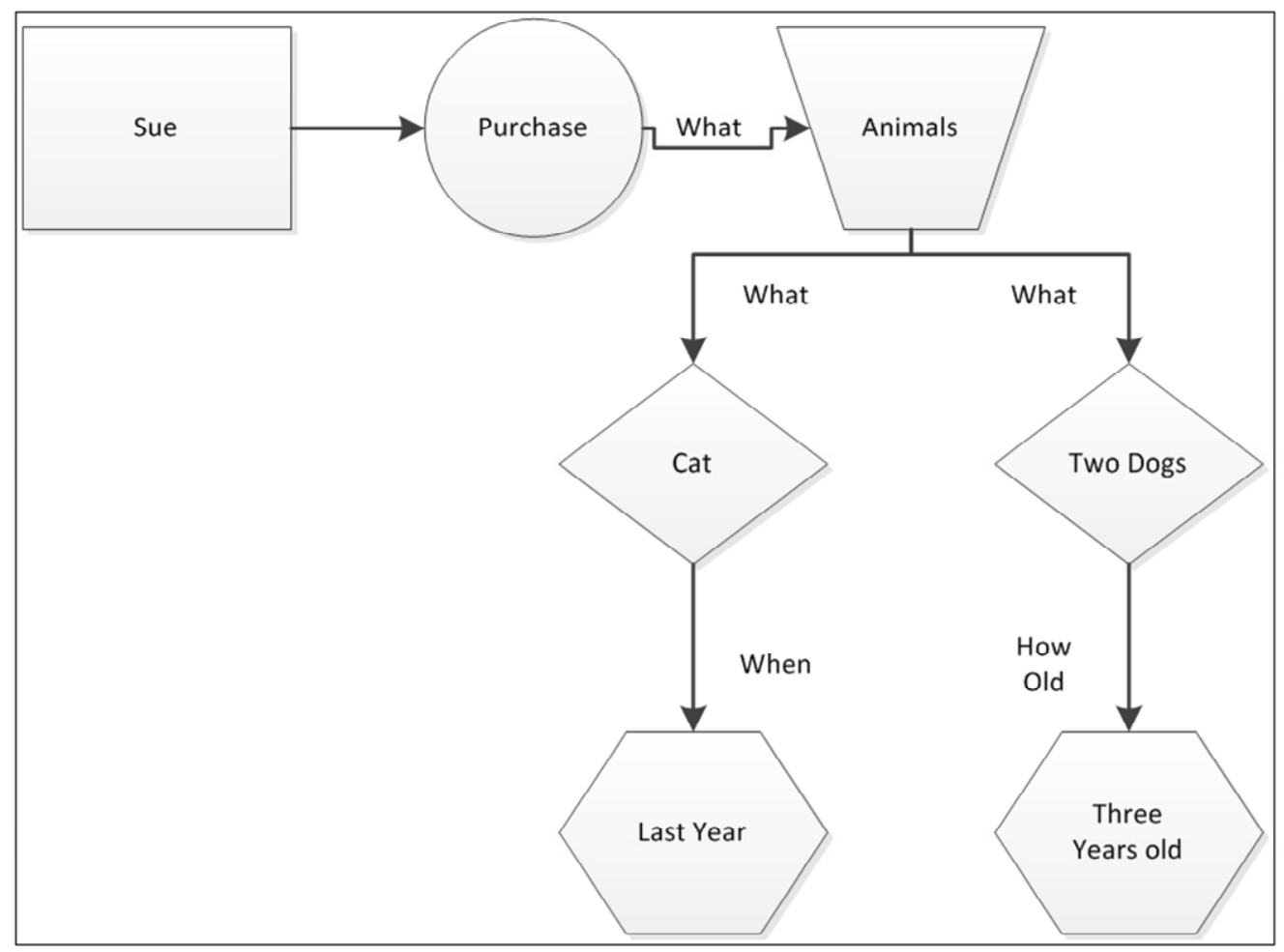

Figure 1. Sample concept map given to the participants.

\section{Results}

\subsection{The effect of concept mapping on listening comprehension}

After ensuring the homogeneity of the experimental and control groups, the participants in both groups were trained in listening in accordance to their treatment conditions; the experimental group was taught fill-in-the-map and collaborative concept mapping techniques and the control group received no instruction on any concept mapping techniques. The participants were instructed for eight sessions. After the treatment, the listening section of the KET was administered to the participants in the control and experimental groups as a post-test. Table 1 displays descriptive statistics of the participants' scores. The result of the $t$-test is shown is Table 2. 
Sabbaghan, S. \& Ansarian, F.

Table 1

Descriptive Statistics of the Post-Test Scores

\begin{tabular}{llccc}
\hline & $\mathrm{N}$ & Mean & Std. Deviation & Std. Error Mean \\
\hline Experimental group & 73 & 18.05 & 2.84 & 0.39 \\
Control group & 73 & 12.48 & 2.33 & 0.57 \\
\hline
\end{tabular}

Table 2

A paired sample t-test

\begin{tabular}{llll}
\hline & $\mathrm{t}$ & $\mathrm{df}$ & $\mathrm{Sig}$ \\
\hline Experimental group & -2.77 & 72 & 0.023 \\
Control group & 1.79 & 72 & 0.139 \\
\hline
\end{tabular}

The results of the $t$-test show that there is a significant difference between the pretest and post-test scores of the experimental group $t_{(72)}=-2.77, p=0.023$. However, no significant difference in scores was found for the control group $t_{(72)}=1.79, p=0.139$. Based on these results, it could be concluded that the introduction and practice of fill-in-the-map and collaborative concept mapping techniques significantly affects EFL learners' listening comprehension ability. Based on the results obtained, we can tentatively state that the employment of the fill-in-the-map and collaborative mapping techniques had a positive effect on EFL learners' listening comprehension skills, as the mean scores of the experimental group was higher than that of the control group $\mathrm{M}_{\text {experimental }}=18.05>\mathrm{M}_{\mathrm{control}}=12.48$.

\subsection{Learners' attitude towards concept mapping}

In the self-assessment questionnaire, Statement 1 and Statement 4 were divergent. These statements were placed to ensure that scoring was not random, and also to avoid scoring bias. In order confirm the lack of response sets or scoring bias, the person product correlation coefficient of Statement 1and statement 4 and the total scores, not including the scores for these statements, were calculated. The results are displayed in Table 3.

Table 3

Correlation coefficient between total scores and statements one and four

\begin{tabular}{lllll}
\hline \multicolumn{2}{c}{ Pretest } & & \multicolumn{2}{c}{ Post-test } \\
Statement 1 - Total & Statement 4 - Total & & Statement 1 - Total & Statement 4 - Total \\
\hline-0.27 & -0.49 & -0.50 & -0.37 \\
\hline
\end{tabular}

The data in Table 3 indicates a negative correlation coefficient for all four coefficients. If scoring was random, or in case that bias was involved, a positive correlation coefficient, or no correlation, would have been expected. However, in this case, it can tentatively be concluded that the scoring of the questionnaires were not random, nor were biased. A Mann-Whietny U test was utilized to compare the participants' self-assessment scores before the introduction of concept mapping and after the post-test in the experimental group. This non-parametric statistical analysis was selected because the scores of the questionnaire were not normally distributed. The result of the Mann-Whitney $U$ is displayed in Table 4.

Table 4

Result of Man-Whitney $U$

\begin{tabular}{llll}
\hline & Man-Whitney U & Sig. & Wilcoxon W \\
\hline Self-Assessment & 153.500 & .000 & 598.500 \\
\hline
\end{tabular}

The results indicate that there is significant difference between the scores of the pretest and the post-test of 
Do they know that they know? EFL learners' attitude towards concept mapping in listening comprehension

the experimental group $U=178.5, p=.000$. Considering that the participants' self-assessment scores increased from a mean of $\mathrm{M}=21.45$ (the mean before concept mapping was introduced) to $\mathrm{M}=39.55$, we can cautiously conclude that the participants' attitudes regarding their listening comprehension abilities became more positive most likely due to the instruction and practice of the concept mapping strategies.

\section{Discussion}

\subsection{The effect of concept mapping on listening comprehension}

Data analysis revealed that the introduction and practice of concept mapping techniques had a positive influence on the listening comprehension ability of the participants. However, there are many factors involved in the study that may have influenced the results. For instance, the manner in which instructions on concept mapping was given to the participants by the researchers might have positively influenced the results. The researchers provided plenty of examples, a detailed account of constructing and completing a concept map, and took time outside the classroom to provide constructive feedback to the learners and deal with the misconceptions that some of the participants had regarding concept mapping. The reality is that many teachers and instructors would simply not have the time to introduce and practice concept maps as elaborately as was done in this study. Had the researchers eliminated the steps not associates with normal instructional routines, the outcome of the data analysis might have been different. Furthermore, as the researchers conducted eight practice sessions, it can be assumed that the general language proficiency of the participants improved and this development might have affected the outcome of the study. Moreover, although the pretest and the post-test were very similar in form and nature, the researchers did not select the topics of the listening. As a result, the topics for the post-test could have been familiar for some of the participants, which might have falsely had a positive influence on the results on the study.

It is the researchers' belief, however, that the major contributor for the increase in the participants' listening comprehension ability was the treatment that was provided on concept mapping techniques. We make this claim by pointing out that the experimental and control groups were homogeneous regarding both language proficiency and listening comprehension ability in the beginning of the study. The control group received instruction on listening compression, and after eight sessions their scores increased slightly, but not significantly. Therefore, it seems highly unlikely that the actions of the instructors had significant effects on the outcome of the study. The more likely scenario is that the instruction and practice of concept mapping techniques was primarily responsible for the outcome.

\subsection{Learners'attitude towards concept mapping}

At the beginning of the study, when the researchers administered the self-assessment questionnaire to the participants, they discovered that almost all the students were not familiar with this method. This discovery was made based on the comments that the participants made regarding concept mapping. The majority of the participants selected the undecided option on the liket scale for the statements in the questionnaire. Furthermore, many participants commented that they were unfamiliar with concept mapping, and some of the participants remarked that they were eager to learn about it.

The data analysis revealed that the participants' attitude towards using concept maps as tool which improves their listening comprehension ability was positive. There were, however, several factors which could have falsely affected the findings. For example, the concept maps were printed on colored paper, which were appealing for the participants, and so a false sense of motivation might have been created resulting in a bogus sense of a positive attitude towards concept maps. Another factor could have been the dynamic and fun atmosphere of the classes which might have positively influenced the opinions of the participants.

However, the researchers believe that the most influential cause of the attitude change was the treatment. 
The researchers make this conclusion based on the comments provided by the participants in the questionnaires completed after the post-test. For example, one of the participants concluded that "before I think it is not good but now I like it." Another commented: "I think it helps my listening." However, some of participants indicated that the process was "difficult to do" and "take long time to finish", indicating that concept mapping is a time-consuming process. There were five participants that believed concept mapping did not help their listening comprehension ability. Even so, most of the comments provided by the participants highlighted the effectiveness of concept mapping and a few specified that they will use this strategy in the future for listening and reading tasks.

\section{Conclusion}

Based on the results of this study, it is our conclusion that integrating concept maps in listening comprehension activities is beneficial for the EFL learners. Moreover, if awareness raising activities are incorporated in tasks that involve concept maps, learners will realize the effectiveness of the tool. Making this realization is important because learners who believe they are learning a useful strategy are apt to feel efficacious about improving their language skills (Schunk, 1989).

An important question to address here is in what way does concept mapping improve listening comprehension? We presume that through concept mapping learners become metacognitively, motivationally, and behaviorally active participants in their own learning processes. They will probably set goals for themselves, and make an effort to achieve these goals. With concept mapping, learner will have concrete evidence of whether and how well their listening comprehension is developing. If they are not able to complete their concept maps correctly, they will probably make modifications to the listening process they employ. If the results they obtain from the adjustments remain unsatisfactory, they will probably seek assistance. In any case, their listening completion ability will improve.

The participants in this study developed a positive attitude towards concept mapping and recognized its potential in developing their listening comprehension skills. Perhaps they might decide to employ this tool often during the time in which they are learning English as a foreign language. As a result, they may become independent and autonomous. Such as outcome is very desirable as encouraging leaner autonomy is one of the pillars of the EFL/ESL teaching (Littlewood, 1984).

\section{References:}

Allen, D. (2004). Oxford placement test. Oxford: Oxford University Press.

Arnaudin, M. W., Mintzes, J. J., Dunn, C. S., \& Shafer, T. (1984). Concept mapping in college science teaching. Journal of College Science Teaching, 14(2), 117-121.

Beyerbach, B. A., \& Smith, J. M. (1990). Using a computerized concept mapping program to assess preservice teachers' thinking about effective teaching. Journal of Research in Science Teaching, 27(10), 961-971. http://dx.doi.org/10.1002/tea.3660271005

Boyle, J. R., \& Weishaar, M. (1997). The effects of expert-generated versus student-generated cognitive organizers on the reading comprehension of students with learning disabilities. Learning Disabilities Research and Practice, 12(4), 228-235.

Brown, H. D. (2007). Teaching by principles: An interactive approach to language pedagogy (3rd ed.). White Plains, NY: Pearson Education.

Celce-Murcia, M., \& McIntosh, L. (1991). Teaching english as a second or foreign language. New York: Heinle \& Heinle Publishers.

Chang, K. E., Sung, Y. T., \& Chen, I. D. (2001). Learning through computer based concept mapping with scaffolding aid. Journal of Computer Assisted Learning, 17(1), 21-33. http://dx.doi.org/10.1046/j.1365-2729.2001.00156.x

Chang, K. E., Sung, Y. T., \& Chen, I. D. (2002). The effect of concept mapping to enhance text comprehension 
Do they know that they know? EFL learners' attitude towards concept mapping in listening comprehension

and summarization. The Journal of Experimental Education, 71(1), 5-23.

http://dx.doi.org/10.1080/00220970209602054

Chularut, P., \& DeBacker, T. K. (2004). The influence of concept mapping on achievement, self-regulation, and self-efficacy in students of english as a second language. Contemporary Educational Psychology, 29(3), 248-263. http://dx.doi.org/10.1016/j.cedpsych.2003.09.001

Conradty, C., \& Bogner, F. (2012). Knowledge presented in concept maps: Correlations with conventional cognitive knowledge tests. Educational Studies, 38(3), 341-354.

http://dx.doi.org/10.1080/03055698.2011.643100

Erdogan, Y. (2009). Paper based and computer based concept mappings: The effects on computer achievement, computer anxiety and computer attitude. British Journal of Educational Technology, 40(5), 821-836. http://dx.doi.org/10.1111/j.1467-8535.2008.00856.x

Fahim, M., \& Amjadiparvar, A. (2012). An investigation of the effect of concept mapping on improving iranian efl learners' listening comprehension ability. Journal of American Science, 8(6).

Goh, C. (2002). Teaching listening in the language classroom. Singapore: SEAMEO Regional Language Centre.

Guvenc, H., \& Acikgoz, K. U. (2007). The effects of cooperative learning and concept mapping on learning strategy use. Educational Sciences: Theory and Practice, 7(1), 117-127.

Horton, P. B., McConney, A. A., Gallo, M., Woods, A. L., Senn, G. J., \& Hamelin, D. (2006). An investigation of the effectiveness of concept mapping as an instructional tool. Science Education, 77(1), 95-111. http://dx.doi.org/10.1002/sce.3730770107

Hwang, G. J., Shi, Y. R., \& Chu, H. C. (2010). A concept map approach to developing collaborative mindtools for context aware ubiquitous learning. British Journal of Educational Technology, 42(5), 778-789. http://dx.doi.org/10.1111/j.1467-8535.2010.01102.x

Igwebuike, T. B. (2012). Effects of conceptual change pedagogy on achievement by high ability integrated science students on energy concepts. International Journal of Research Studies in Educational Technology, 2(1). http://dx.doi.org/10.5861/ijrset.2012.123

Jegede, O. J., Alaiyemola, F. F., \& Okebukola, P. A. O. (1990). The effect of concept mapping on students' anxiety and achievement in biology. Journal of research in science teaching, 27(10), 951-960. http://dx.doi.org/10.1002/tea.3660271004

Jonassen, D. H., Beissner, K., \& Yacci, M. (1993). Structural knowledge: Techniques for representing, conveying, and acquiring structural knowledge. Hillsdale, NJ: Lawrence Erlbaum.

Kinchin, I., \& Hay, D. (2005). Using concept maps to optimize the composition of collaborative student groups: A pilot study. Journal of Advanced Nursing, 51(2), 182-187. http://dx.doi.org/10.1111/j.1365-2648.2005.03478.x

Kintsch, W., \& Van Dijk, T. A. (1978). Toward a model of text comprehension and production. Psychological review, 85(5), 363. http://dx.doi.org/10.1037/0033-295X.85.5.363

Kwon, S. Y., \& Cifuentes, L. (2009). The comparative effect of individually-constructed vs. Collaboratively-constructed computer-based concept maps. Computers \& Education, 52(2), 365-375. http://dx.doi.org/10.1016/j.compedu.2008.09.012

Littlewood, W.T. (1984). Foreign and second language learning Cambridge: Cambridge University Press.

Liu, P. L., Chen, C. J., \& Chang, Y. J. (2010). Effects of a computer-assisted concept mapping learning strategy on efl college students' english reading comprehension. Computers \& Education, 54(2), 436-445. http://dx.doi.org/10.1016/j.compedu.2009.08.027

Mayer, R. E. (1996). Learning strategies for making sense out of expository text: The soi model for guiding three cognitive processes in knowledge construction. Educational psychology review, 8(4), 357-371. http://dx.doi.org/10.1007/BF01463939

McCagg, E. C., \& Dansereau, D. F. (1991). A convergent paradigm for examining knowledge mapping as a learning strategy. The Journal of Educational Research, 84(6), 317-324. http://dx.doi.org/10.1080/00220671.1991.9941812

Novak, J. D. (1990). Concept maps and vee diagrams: Two metacognitive tools for science and mathematics education. Instructional Science, 19(1), 29-52. http://dx.doi.org/10.1007/BF00377984 
Sabbaghan, S. \& Ansarian, F.

Novak, J. D., Bob Gowin, D., \& Johansen, G. T. (1983). The use of concept mapping and knowledge vee mapping with junior high school science students. Science Education, 67(5), 625-645. http://dx.doi.org/10.1002/sce.3730670511

Nunan, D. (1999). Second language teaching \& learning. Boston: Heinle \& Heinle.

Nunan, D. (2002). Listening in language learning. In J. C. Richards \& W. A. Renandya (Eds.), Methodology in language teaching: An anthology of current practice (pp. 238-241). Cambridge: Cambridge University Press. http://dx.doi.org/10.1017/CBO9780511667190.032

Ojima, M. (2006). Concept mapping as pre-task planning: A case study of three japanese esl writers. System, 34(4), 566-585. http://dx.doi.org/10.1016/j.system.2006.08.003

Okebukola, P. A., \& Jegede, O. J. (1989). Students' anxiety towards and perception of difficulty of some biological concepts under the concept mapping heuristic. Research in Science \& Technological Education, 7(1), 85-92. http://dx.doi.org/10.1080/0263514890070109

Rost, M. (1991). Listening in action: Activities for developing listening in language teaching. New York: Prentice Hall.

Rost, M. (2001). Listening. In R. Carter \& D. Nunan (Eds.), The cambridge guide to teaching english to speakers of other languages (pp. 7-13). Cambrige: Cambridge University Press.

Ruddell, R. B., \& Boyle, O. F. (1989). A study of cognitive mapping as a means to improve summarization and comprehension of expository text. Literacy Research and Instruction, 29(1), 12-22.

Ruiz-Primo, M. A. (2000). On the use of concept maps as an assessment tool in science: What we have learned so far. Revista Electrónica de Investigación Educativa, 2(1), 30-52.

Scanlon, D. J. (1992). Interactive semantic mapping: An interactive approach to enhancing ld students' content area comprehension. Learning Disabilities Research and Practice, 7(3), 142-146.

Schau, C., Mattern, N., Weber, R., Minnick, K., \& Witt, C. (1997). Use of fill-in concept maps to assess middle school students' connected understanding of science. Paper presented at the AERA Annual Meeting, Chicago, IL.

Schunk, D. H. (1989). Self-efficacy and achievement behaviors. Educational Psychology Review, 1(3), 173-208. http://dx.doi.org/10.1007/BF01320134

Sturm, J. M., \& Rankin-Erickson, J.L. (2002). Effects of hand-drawn and computer-generated concept mapping on the expository writing of middle school students with learning disabilities. Learning Disabilities Research \& Practice, 17(2), 124-139. http://dx.doi.org/10.1111/1540-5826.00039

Talebinezhad, M. R., \& Negari, G. M. (2007). The effect of explicit teaching of concept mapping in expository writing on efl students' self-regulation. The Linguistics Journal, 2(1), 69-90.

Tripto, J., Assaraf, O. B., \& Amit, M. (2013). Mapping what they know: Concept maps as an effective tool for assessing students' systems thinking. American Journal of Operations Research, 3, 245-258. http://dx.doi.org/10.4236/ajor.2013.31A022

Tzeng, J. Y. (2010). Designs of concept maps and their impacts on readers' performance in memory and reasoning while reading. Journal of Research in Reading, 33(2), 128-147. http://dx.doi.org/10.1111/j.1467-9817.2009.01404.x

Ur, P. (1984). Teaching listening comprehension. Cambride: Cambridge University Press.

Yen, J. C., Lee, C. Y., \& Chen, I. (2012). The effects of image-based concept mapping on the learning outcomes and cognitive processes of mobile learners. British Journal of Educational Technology, 43(2), 307-320. http://dx.doi.org/10.1111/j.1467-8535.2011.01189.x 


\section{Appendix A}

\section{Self-assessment questionnaire}

\begin{tabular}{|l|l|l|l|l|l|l|}
\hline Items & $\begin{array}{l}\text { Strongly } \\
\text { disagree }\end{array}$ & Disagree & Undecided & Agree & $\begin{array}{l}\text { Strongly } \\
\text { agree }\end{array}$ & Comments \\
\hline $\begin{array}{l}\text { 1. It is difficult to understand concept } \\
\text { mapping. }\end{array}$ & & & & & & \\
\hline $\begin{array}{l}\text { 2. I like talking about my concept maps } \\
\text { with friends. }\end{array}$ & & & & & & \\
\hline $\begin{array}{l}\text { 3. I like teachers to present concept } \\
\text { maps. }\end{array}$ & & & & & & \\
\hline 4. Concept mapping is a waste time. & & & & & \\
\hline $\begin{array}{l}\text { 5. Completing concept maps in class } \\
\text { helps me learn and understand better. }\end{array}$ & & & & & & \\
\hline $\begin{array}{l}\text { 6. I like to use concept map for exams } \\
\text { and quizzes. }\end{array}$ & & & & & & \\
\hline $\begin{array}{l}\text { 7. I like using concept maps to listen to a } \\
\text { passage. }\end{array}$ & & & & & & \\
\hline 8. Concept mapping is enjoyable. & & & & & & \\
\hline $\begin{array}{l}\text { 9. Concept mapping helps me understand } \\
\text { difficult listening passages. }\end{array}$ & & & & & & \\
\hline 10. Concept maps show your knowledge. & & & & & & \\
\hline
\end{tabular}

\section{Appendix B}

\section{Sample fill-in-the-map concept map}

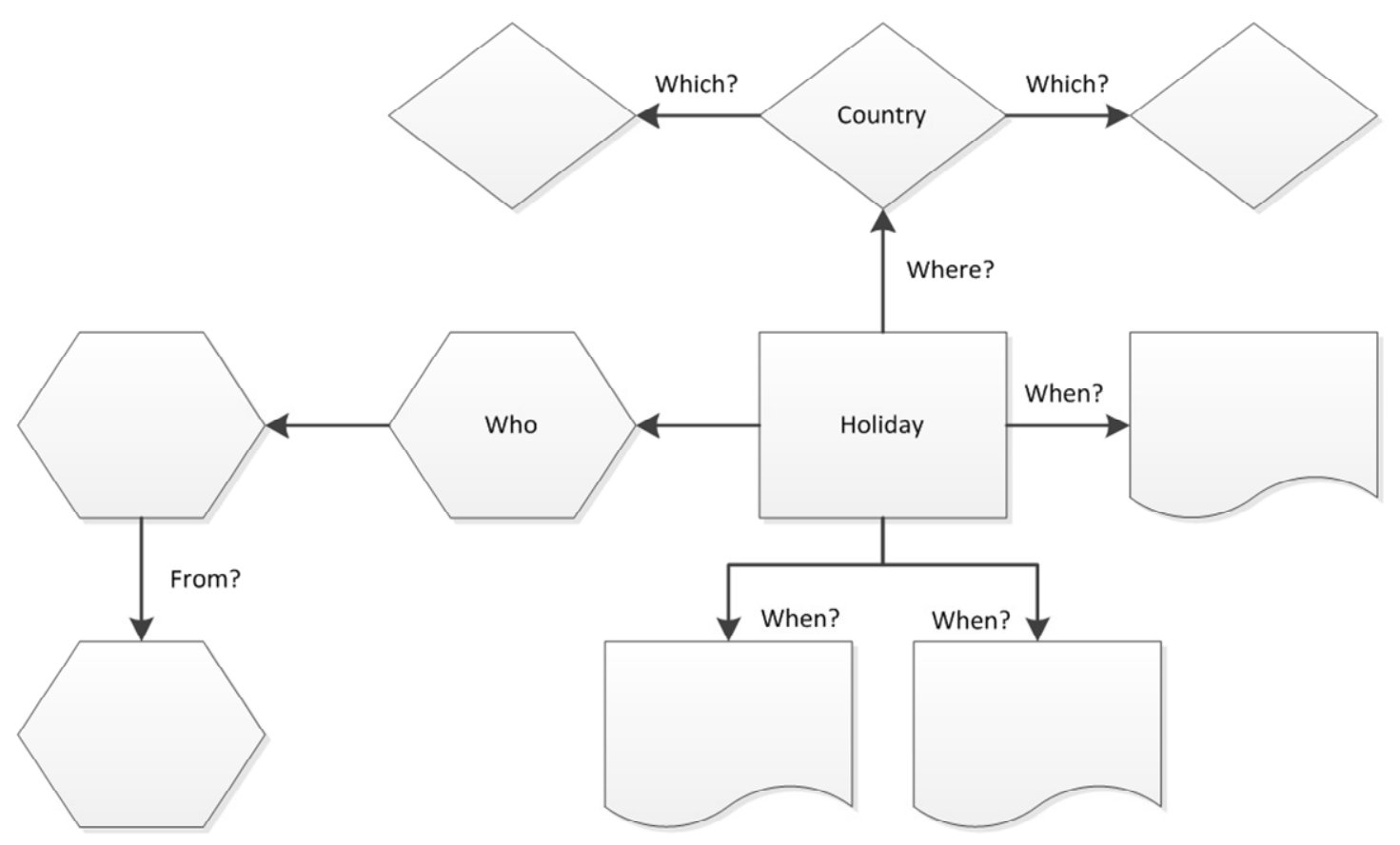


Sabbaghan, S. \& Ansarian, F. 